\title{
Northern magnetic displacements trigger endogenous fuelling responses in a naive bird migrant
}

\author{
Jannika E. Boström • Cecilia Kullberg • \\ Susanne Åkesson
}

Received: 13 October 2011 /Revised: 5 February 2012 / Accepted: 7 February 2012 /Published online: 10 March 2012

(C) Springer-Verlag 2012

\begin{abstract}
In a previous study, we found that juvenile northern wheatears (Oenanthe oenanthe) exposed to a magnetic displacement to the west of their natural migration route increased their body mass. The total intensity and inclination used for the western displacement may also have been interpreted as northern compared to the experimental site (stronger total field intensity and steeper inclination angle). In order to investigate whether the fuelling response was a response to an unexpected magnetic field or specific to the northern magnetic field, we conducted a new experiment. Juvenile wheatears from the same study population were magnetically displaced to southwestern magnetic fields, exposing the birds to unexpected magnetic combinations, but eliminating the possible effect of a northern magnetic field. A control group was kept in the local geomagnetic field in Sweden for comparison. There was no difference in body mass increase between treatments, suggesting that the fuelling response previously found was not a simple response to an unexpected magnetic field, but rather a specific response to the northern magnetic field. Juvenile wheatears may have developed a fuelling response to northern magnetic fields in order to enable a successful flight towards the migration goal.
\end{abstract}

Communicated by W. Wiltschko

J. E. Boström $(\bowtie) \cdot$ S. Åkesson

Department of Biology, Lund University,

Ecology Building,

22362 Lund, Sweden

e-mail: jannika.bostrom@biol.lu.se

C. Kullberg

Department of Zoology, Stockholm University,

10691 Stockholm, Sweden
Keywords Magnetic field · Fuelling · Migration programs · Northern wheatear

In an earlier study, we reported that wild-caught Swedish juvenile wheatears experiencing a magnetic, but not geographic displacement to the west of their natural migration route (hereafter called 'treatment $\mathrm{w}_{\mathrm{w}}$ ') increased more in body mass than individuals experiencing a simulation of their population-specific migration route through western Europe ('treatment ${ }_{\text {mig' }}$ ) (Boström et al. 2010). The magnetic parameters used for the western displacement, however, also translate into a northern magnetic field relative to the experimental site (i.e., stronger total field intensity and steeper inclination angle; Fig. 1). In order to determine whether the difference in body mass was caused by an unexpected magnetic field or an exposure to a northern magnetic field, we here present a follow-up experiment performed in autumn of 2009. Juvenile wheatears were caught with spring traps at Ottenby Bird Observatory $\left(56^{\circ} 12^{\prime} \mathrm{N}, 16^{\circ} 24^{\prime} \mathrm{E}\right)$ in late July 2009. The birds were brought to Stensoffa Ecological Field Station $\left(55^{\circ} 42^{\prime} \mathrm{N}, 13^{\circ} 25^{\prime} \mathrm{E}\right)$ where they were kept individually in outdoor aviaries for 30 days before transportation to the experimental site. We used the same method and experimental setup as in Boström et al. (2010), but excluded the northernmost position in the treatment (Atlantic 1 in Boström et al. 2010) and only used magnetic parameters corresponding to south-western displacements ('treatment ${ }_{\mathrm{sw}}$ '; Fig. 1 and Table 1). One group was kept in the ambient magnetic field at the experimental site for comparison ('treatment ${ }_{S w e}$ '). The results were compared to the previous study (performed in 2007; Boström et al. 2010). There was no difference in wing length between years (independent samples $t$ test, $t_{1,22}=-0.17, p=0.87$ ). 


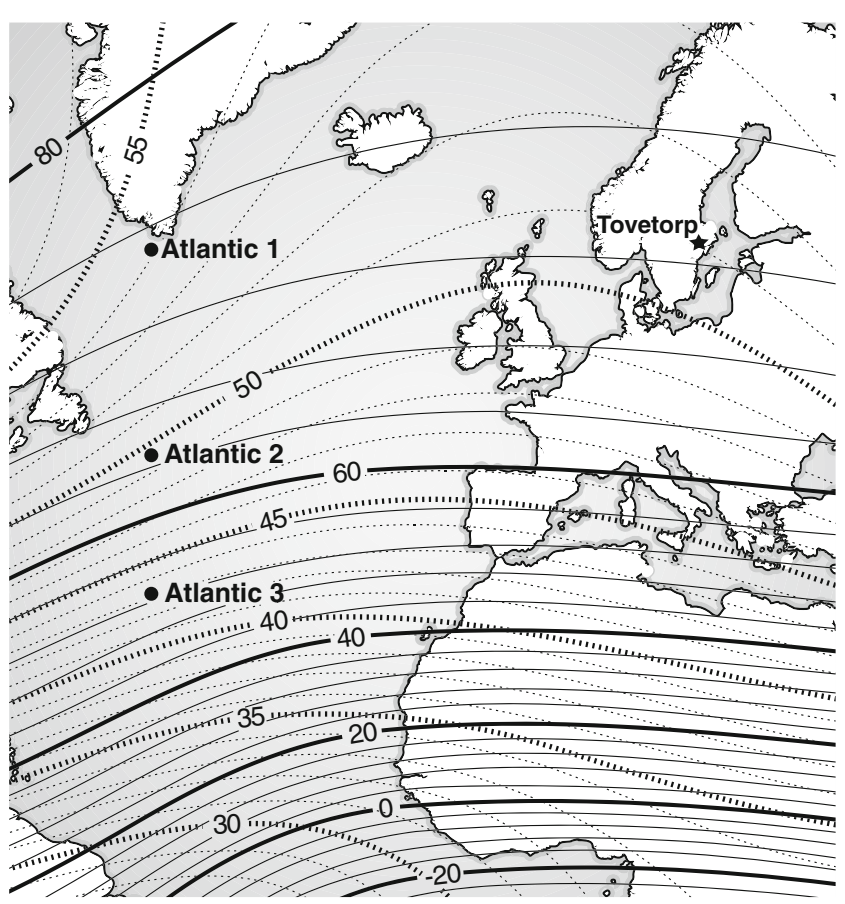

Fig. 1 Geographic positions corresponding to the magnetic fields used for the simulated displacements. Treatment ${ }_{\text {swe }}$ birds were kept in the ambient magnetic field at Tovetorp and treatment ${ }_{\mathrm{Sw}}$ birds were displaced to Atlantic 2 and 3. In our previous experiment, the displaced wheatears were displaced to Atlantic 1 and 2 (Boström et al. 2010). The hatched lines show the total field intensity (micro Tesla) and the solid lines show the inclination (in degrees). Both the total field intensity and the inclination experienced at Atlantic 1 also correspond to geographical positions north of Tovetorp, where the experiments were conducted

Initial body mass did not differ between treatments within years (independent sample $t$ tests, 2007, $t_{1,10}=1.57, p=$ 0.14 ; treatment $_{\text {migr }}, 26.5 \pm 3.6 \mathrm{~g}$; treatment $_{\mathrm{W}}, 28.8 \pm 2.0 \mathrm{~g}$; $2009, t_{1,12}=0.41, p=0.7$; treatment $_{\text {Swe }}, 22.7 \pm 2.6 \mathrm{~g}$; treatment $_{\mathrm{SW}}, 23.1 \pm 1.5 \mathrm{~g}$ ). There was however a difference in initial body mass between years $\left(t_{1}, 24=5.96, p<0.001\right.$; $2007,28.5 \pm 2.7 \mathrm{~g} ; 2009,22.9 \pm 2.0 \mathrm{~g}$ ), probably because birds were held indoors in more restricted spaces before the experiment in 2007 while they were held in outdoor aviaries in 2009. Juvenile wheatears experiencing a

Table 1 Magnetic fields used for the displacements and their corresponding geographical locations

\begin{tabular}{llll}
\hline Location & Position & Total intensity (nT) & Inclination $\left(^{\circ}\right)$ \\
\hline Tovetorp & $58^{\circ} 56^{\prime} \mathrm{N}, 17^{\circ} 08^{\prime} \mathrm{E}$ & 50,900 & 72.3 \\
${\text { Atlantic } 1^{\mathrm{a}}}^{\mathrm{a}}$ & $58^{\circ} 57^{\prime} \mathrm{N}, 45^{\circ} 00^{\prime} \mathrm{W}$ & 53,800 & 74.7 \\
Atlantic 2 & $45^{\circ} 00^{\prime} \mathrm{N}, 45^{\circ} 00^{\prime} \mathrm{W}$ & 49,100 & 64.0 \\
Atlantic 3 & $33^{\circ} 00^{\prime} \mathrm{N}, 45^{\circ} 00^{\prime} \mathrm{W}$ & 42,800 & 52.0
\end{tabular}

Magnetic parameters given for the WWM 2005 model (McLean et al. 2004)

${ }^{\mathrm{a}}$ Displacement only used for treatment ${ }_{\mathrm{W}}$ (Boström et al. 2010) displacement in the migratory direction (treatment $t_{\mathrm{SW}}$ ) did not increase their body mass compared to wheatears kept in the ambient magnetic field (ANOVA with increase in body mass from day 1 as repeated measurement; effect of treatment, $F_{1,12}=0.009, p=0.9$; effect of day $\times$ treatment, $F_{13}$, ${ }_{156}=0.08 ; p=0.9$ ). 'Treatment ${ }_{\mathrm{W}}$ ' resulted in higher final body mass compared to all other treatments (ANOVA, $d f=$ $3, F_{3,22}=3.03, p=0.05$; post hoc significant differences Fisher LSD,$d f=22$; treatment $_{\mathrm{W}}$ compared to treatment $_{\text {migr }}$, $p=0.01$; treatment Swe $_{\text {e }}, p=0.03$; treatment $_{\mathrm{SW}}, p=0.047$; Fig. 2). The lower body masses of the other treatments probably mirror the relatively small fuel loads recorded in wheatears throughout Europe (Delingat et al. 2006). The fact that wheatears did not increase their body mass in south-western magnetic fields, even though they were exposed to unexpected magnetic fields, suggests that the higher body mass shown in treatment ${ }_{\mathrm{W}}$ (Boström et al. 2010) is a specific response to the simulated northern displacement experienced by the birds. Since there was no difference in wing length between years, all the birds could be expected to be able to fly approximately the same distance at any given body mass. This means that at the end of our experiment, the three treatments that did not differ significantly in body mass were all prepared for a similar flight step and the treatment group that had a higher body mass was prepared for a longer flight step. Our results, thus, suggest that juvenile wheatears are able to detect a latitudinal displacement based on total field intensity and/or inclination. A study by Schiffner and Wiltschko (2011) showed that homing pigeons are able to determine latitude based on magnetic intensity on a local scale, and the wheatears in our experiments may have used the total field intensity to determine the direction of displacement. Whether migratory birds are able to detect $\mathrm{E}-\mathrm{W}$ displacements based only on magnetic parameters is unknown ( $\AA$ kesson et al. 2005; Gould 2008), hence we can only conclude that the young wheatears did not respond to the unexpected magnetic combinations

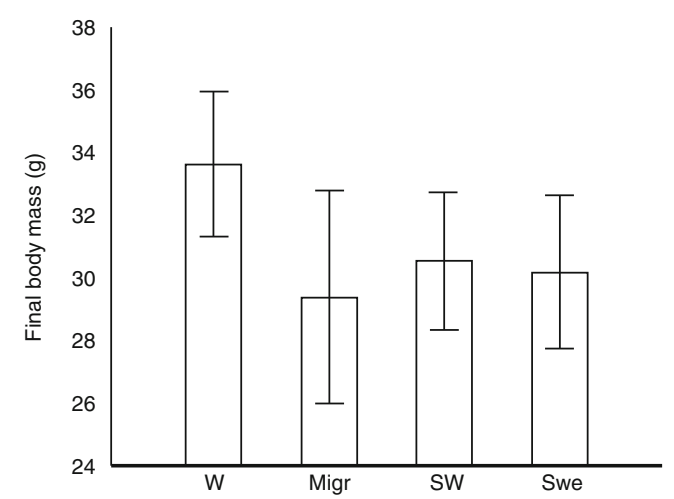

Fig. 2 Final body mass $( \pm \mathrm{SE})$ of juvenile wheatears in the four different treatments in 2007 and 2009. The number of individuals in each group is: treatment ${ }_{\mathrm{W}}$, six; treatment $_{\text {migr }}$, six; treatment ${ }_{\mathrm{SW}}$, eight, and treatment ${ }_{\text {Swe }}$, eight 
experienced in treatment ${ }_{\mathrm{SW}}$. All but one treatment group ended up at similar final body masses (Fig. 2), suggesting that these treatments were all prepared for similar flight ranges. Fuelling regulation has been shown to be endogenously controlled in three populations of wheatears (Maggini and Bairlein 2010) and our results support this finding. If the wheatears have a migration program integrating the magnetic field experienced and time of season, a northern displacement may translate into a delay or an increased migration distance, triggering a fuelling response to prepare the wheatears for a faster migration southwards. Delayed migratory birds often speed up migration (e.g., Bensch and Nielsen 1999), requiring larger fuel loads and fewer stopovers (e.g., Schaub and Jenni 2000a, b). This response is also in agreement with a genetic program integrating magnetic latitude and time of season to enable the birds to make relevant fuelling decisions in preparation for a longer migratory flight. This program is probably not based on exact geomagnetic positions, but rather on an expected balance between the magnetic latitude and the seasonal time program. A program like this would enable the migrant to start preparing for a barrier crossing already before the actual barrier is within reach, since the program could involve, e.g., a seasonal fuelling response to lower magnetic latitudes in autumn.

Acknowledgments We are grateful to C. Sjöholm and Ottenby Bird Observatory for assistance during bird capture, to R. Stach and S. Jakobsson for help during experiments, and to E. Assarsson for help with the figures. T. Alerstam and two anonymous referees gave valuable comments on an earlier version of this manuscript. Financial support was received from the Swedish Research Council (to S.A. and C.K.) and from Helge Ax:son Johnsons stiftelse (to J.B.). This is report number 252 from Ottenby Bird Observatory.
Ethical standards The study was carried out with permission from the Swedish Animal Welfare Agency (Malmö-Lund, nos. M172-06 and M204-06).

\section{References}

Åkesson S, Morin J, Muheim R, Ottosson U (2005) Dramatic orientation shift of white-crowned sparrows displaced across longitudes in the high arctic. Curr Biol 15:1591-1597

Bensch S, Nielsen B (1999) Autumn migration speed of juvenile reed and sedge warblers in relation to date and fat loads. Condor 101:153-156

Boström JE, Fransson T, Henshaw I, Jakobsson S, Kullberg C, Åkesson S (2010) Autumn migratory fuelling: a response to simulated magnetic displacements in juvenile wheatears, Oenanthe oenanthe. Behav Ecol Sociobiol 64:1725-1732. doi:10.1007/s00265-010-0985-1

Delingat J, Dierschke V, Schmaljohann H, Mendel B, Bairlein F (2006) Daily stopovers as optimal migration strategy in a long-distance migrating passerine: the Northern Wheatear Oenanthe oenanthe. Ardea 94:593-605

Gould JL (2008) Animal navigation: the longitude problem. Curr Biol 18:R214-R216. doi:10.1016/j.cub.2008.01.011

Maggini I, Bairlein F (2010) Endogenous rhythms of seasonal migratory body mass changes and nocturnal restlessness in different populations of northern wheatear Oenanthe oenanthe. J Biol Rhythms 25:268-276. doi:10.1177/0748730410373442

McLean S, Macmillan S, Maus S, Lesur V, Thomson A, Dater D (2004) The US/UK world magnetic model for 2005-2010, NOAA technical report NESDIS/NGDC-1

Schaub M, Jenni L (2000a) Body mass of six long-distance migrant passerine species along the autumn migration route. J Ornithol 141:441-460. doi:10.1007/BF01651574

Schaub M, Jenni L (2000b) Fuel deposition of three passerine bird species along the migratory route. Oecologica 122:306-317. doi: $10.1007 / \mathrm{s} 004420050036$

Schiffner I, Wiltschko R (2011) Temporal fluctuations of the geomagnetic field affect pigeons' entire homing flight. J Comp Physiol A 197:765-772. doi:10.1007/s00359-011-0640-y 